\title{
Characterization of ovarian culture in vitro and sex steroids in vivo by recombinant eel gonadotropin treatments in the eel Anguilla japonica
}

\author{
Dae-Geun Kim ', Jung-Hyun Kim², Hea-Ja Baek ${ }^{3}$, Shin-Kwon Kim ${ }^{4}$ Kwan-Sik Min ${ }^{5, *}$, Dae-Jung Kim ${ }^{2, *}$ \\ ${ }^{1}$ Gyeongsangnam-do Fisheries Resources Research Institute, Tongyeong 53080, Korea \\ ${ }^{2}$ Jeju Fisheries Research Institute, National Institute of Fisheries Science, Jeju 63610, Korea \\ ${ }^{3}$ Department of Marine Biology, Pukyong National University, Busan 48513, Korea \\ ${ }^{4}$ Department of Aquaculture Research, National Institute of Fisheries Science, Busan 46083, Korea \\ ${ }^{5}$ Animal Biotechnology, Graduate School of Future Convergence Technology, School of Animal Life Convergence Science, Institute of Genetic \\ Engineering, Hankyong National University, Anseong 17579, Korea
}

\begin{abstract}
In the present study, we investigated the effects of recombinant eel gonadotropins (rec-GTHs) on maturation induction in immature ovarian culture in vitro and sex steroid hormones in vivo in the Japanese eel Anguilla japonica. To study the in vitro effects of rec-GTHs on estradiol-17 $\beta$ (E2) production in immature ovarian tissues, ovarian tissues were incubated with different doses of rec-follicle-stimulating hormone (rec-FSH) or rec-luteinizing hormone (rec-LH). The results revealed that the E2 levels in the rec-FSH $(0.1,0.5$, or $1 \mu \mathrm{g} / \mathrm{mL})$ - and rec-LH $(0.1$ or $0.5 \mu \mathrm{g} / \mathrm{mL})$-treated groups were significantly higher than those in the female eels from the control group. Furthermore, to investigate the in vivo effects of rec-GTHs on the gonadosomatic index (GSI) and plasma sex steroid hormone levels, the eels were injected intraperitoneally with eel's ringer (control), salmon pituitary extract (SPE; for female eels), human chorionic gonadotropin (hCG; for male eels), rec-FSH, rec-LH, and rec-FSH + rec-LH once a week. The results revealed that except for the SPE and the hCG groups, none of the groups exhibited a significant difference in GSI values. However, in vivo plasma E2 levels increased at the end of 4 weeks after rec-FSH treatment in female eels. Based on these results, it is suggested that rec-GTHs may have a positive effect on sexual maturation in female eels; however, further studies on complementary rec-protein production systems and additional glycosylation of rec-hormones are needed to elucidate hormone bioactivity in vivo and in vitro.
\end{abstract}

Keywords: Eel Anguillajaponica, Gonadotropin, Sexual maturation, Recombinant hormone

Received: Dec 14, 2020 Revised: Sep 6, 2021 Accepted: Nov 17, 2021

${ }^{\star}$ Corresponding author: Dae-Jung Kim

Jeju Fisheries Research Institute, National Institute of Fisheries Science, Jeju 63610, Korea

Tel: +82-64-750-4310, E-mail: djkim4128@korea.kr

*Corresponding author: Kwan-Sik Min

Animal Biotechnology, Graduate School of Future Convergence Technology, School of Animal Life Convergence Science, Institute of Genetic Engineering, Hankyong National University, Anseong 17579, Korea

Tel: +82-31-670-5421, E-mail: ksmin@hknu.ac.kr

This is an Open Access article distributed under the terms of the Creative Commons Attribution Non-Commercial License (http://creativecommons.org/licenses/by$\mathrm{nc} / 4.0 /$ ) which permits unrestricted non-commercial use, distribution, and reproduction in any medium, provided the original work is properly cited.

Copyright $\odot 2022$ The Korean Society of Fisheries and Aquatic Science 


\section{Introduction}

In fish, gonadal development and maturation are regulated by two gonadotropins (GTHs): follicle-stimulating hormone (FSH) and luteinizing hormone (LH). FSH mainly regulates vitellogenesis in females and initiation of spermatogenesis in males; thereafter, LH mainly regulates oocyte maturation in females and spermiation in males. FSH and LH secreted by the pituitary gland are glycoprotein hormones comprising an $\alpha$-subunit and a $\beta$-subunit (Kim et al., 2005; Yaron et al., 2003). Although the $\alpha$-subunits are common to these glycoproteins, the $\beta$-subunits are unique to each hormone (Byambaragchaa et al., 2018; Combarnous, 1992; Kim et al., 2016; Min et al., 1996).

A stable supply of seedlings and control of sex maturation of the bloodstock is very important for fish culture (Hamidoghli et al., 2019). However, in the case of female eels, the induction of sexual maturity is very difficult in artificial environmental conditions (Ijiri et al., 2011; Tanaka, 2015) because they have a very low ability to synthesize GTHs from the pituitary gland in such an environment (Kagawa et al., 1998; Kim et al., 2007). Therefore, a high concentration of exogenous hormones is periodically administered to induce sexual maturity. In the case of Anguilla japonica, gonadal development can be induced by salmon pituitary extract (SPE) administration (Kagawa et al., 1998, Kim et al., 2007; Tanaka et al., 2001; Yamamoto \& Yamauchi, 1974). However, it has also been reported that repeated exposure of female eels to high doses of exogenous hormones results in eggs of poor quality, and fertilization malformations (Okamura et al., 2011; Shin, 2004). Likewise, spermiation of fishes, including eels, could be induced by human chorionic gonadotropin (hCG) as an LH effect (Miura et al., 1991). However, the duration of the spermiation and the quality of milt following hCG administration showed large individual differences in male eels (Kim et al., 2018; Otha et al., 1997). To solve these problems, it is necessary to develop a gonadotropic reagent for stable artificial seed production that improves egg quality and quantity.

Advancements in biotechnology have made it possible to isolate and clone the GTH genes of a variety of fishes (Choi et al., 2005; Kim et al., 2005) and to produce species-specific recombinant GTHs (rec-GTHs) using invertebrate bioreactor systems (Choi et al., 2016; Kazeto et al., 2008; Kobayashi et al., 2010). Furthermore, biological activity assays are being conducted by investigating the in vivo and in vitro effects of recGTHs in fish (Byambaragchaa et al., 2018; Kamei et al., 2003; Kim et al., 2017; Kim et al., 2019; Ko et al., 2007; Vischer et al.,
2003). In particular, in our previous study, a baculovirus system was used to produce recombinant GTHs in an eel, and the biological activities of rec-GTHs were examined by measuring the percentage of germinal vesicle breakdown in vitro (Choi et al., 2016). The assay results revealed that rec-GTHs were positively involved in the induction of maturation under in vitro conditions (Choi et al., 2016). However, the in vivo effect of rec-GTHs on sexual maturity in female eels, and the biological activity of recombinant hormones in male eels had not been investigated.

In the present study, we attempted to produce rec-eel FSH and rec-eel $\mathrm{LH}$ from CHO-suspension (CHO-S) cell line, and assayed their biological effects on female and male eels both in vitro and in vivo.

\section{Materials and Methods}

\section{Experimental fish breeding management}

Male Japanese eels (approximately 300-500 g each) and female eels (approximately 450-500 g each) were cultured in 1-ton tanks with aerated fresh water at a temperature of $20 \pm 0.5^{\circ} \mathrm{C}$, at the Inland Aquaculture Research Center, National Institute of Fisheries Science, Changwon. 20 male eels and 20 females were used in the experiment. All eels were acclimatized to seawater for one week before the experiment. A black shade film was installed on the water tank to stabilize the fish. Furthermore, ID microchips ( $\oint 2.1 \times 12 \mathrm{~mm}$ ) were inserted into the dorsal muscles for individual control of each eel, and a mini portable reader (HS5900LF, DESTRON Technologies, Kenilworth, NJ, USA) was used for identification.

\section{Production of recombinant gonadotropin proteins from CHO-K1 cells}

cDNAs encoding eel $\mathrm{LH} \beta / \alpha$ and eel $\mathrm{FSH} \beta / \alpha$ were inserted into the pcDNA3 mammalian expression vector as previously reported (Byambaragchaa et al., 2018; Kim et al., 2016; Kim et al., 2019). CHO-S cells were transfected using the liposome transfection method, as previously described (Byambaragchaa et al., 2018; Kim et al., 2019). In brief, both plasmids were transfected into CHO-S cells using the FreeStyle MAX reagent transfection method. One day before transfection, CHO-S cells were passaged at a density of $5 \times 10^{5}$ cells $/ \mathrm{mL}$. The flasks were placed on an orbital shaker platform rotating at $360-405 \times \mathrm{g}$ at $37^{\circ} \mathrm{C}$ in a humidified atmosphere of $8 \% \mathrm{CO}_{2}$ in air. The next day, $260 \mu \mathrm{g}$ of plasmid DNA was diluted in OptiPRO ${ }^{\mathrm{TM}}$ serum-free medium to a total volume of $4 \mathrm{~mL}$. A total of $260 \mu \mathrm{L}$ of FreeStyle ${ }^{\mathrm{TM}}$ MAX reagent was diluted in Opti- 
$\mathrm{PRO}^{\mathrm{TM}}$ serum-free medium to a total volume of $4 \mathrm{~mL}$. DNA-FreeStyle ${ }^{\mathrm{TM}}$ MAX was mixed and incubated for $10 \mathrm{~min}$ at room temperature. Then, the complex mixture was slowly added to $200 \mathrm{~mL}$ of medium containing the cells. The culture media were collected on day 7 after transfection and centrifuged at $100,000 \times \mathrm{g}$ at $4{ }^{\circ} \mathrm{C}$ for $10 \mathrm{~min}$ to remove cell debris. The supernatant samples were concentrated by freeze-drying. Recombinant proteins for eel LH and eel FSH were analyzed using an enzyme-linked immunosorbent assay as previously described (Kim et al., 2016).

\section{In vitro ovarian tissue culture and sex hormone measurement}

Healthy eels were anesthetized with 2-phenoxyethanol (200 ppm), and the ovaries were removed to measure the gonadosomatic index (GSI) (gonadal weight/body weight). The ovarian tissue of GSI 2.3 was sectioned to $100 \mathrm{mg}$, and then a fragment (100 mg) of the ovarian tissue was cultured in each well of 24well plates $(n=6)$. L-15 medium (penicillin G sodium $70 \mathrm{mg}$ / $\mathrm{L}$, streptomycin $100 \mathrm{mg} / \mathrm{L}$, HEPES $10 \mathrm{mM}$, pH 7.4) was used for the culture of ovarian tissue and incubated at $20{ }^{\circ} \mathrm{C}$ for $2 \mathrm{~h}$. Then, rec-follicle-stimulating hormone (rec-FSH) and rec-LH, rec-luteinizing hormone (rec-LH) were added at concentrations of $0.05,0.1,0.5$, and $1 \mu \mathrm{g} / \mathrm{mL}$ per well and incubated at $20^{\circ} \mathrm{C}$ for $24 \mathrm{~h}$. At the end of the incubation, the culture media were collected, and estradiol-17 $\beta$ (E2) concentration was measured using an ELISA kit (DRG, Estradiol ELISA, EIA-2693).

\section{In vivo hormonal treatment of female eel: measurement of sex hormones and gonadosomatic index (GSI)}

Female eels weighing 450-500 g each, were injected intramuscularly with eel's ringer (control), SPE (20 mg/fish), rec-FSH (0.1 $\mu \mathrm{g} / \mathrm{g}$ BW $)$, rec-LH $(0.1 \mu \mathrm{g} / \mathrm{g}$ BW $)$, and rec-FSH + rec-LH (0.05 $\mu \mathrm{g}+0.05 \mu \mathrm{g} / \mathrm{g} \mathrm{BW}$ ) once a week. After 4 and 8 injections, 8-10 eels from each experimental group were collected for blood sampling and GSI measurements. Blood samples were taken from the caudal vasculature with a heparinized 1-mL syringe and needle (23G) after anesthetization with 2-phenoxyethanol (200 ppm). The blood samples were centrifuged at $4{ }^{\circ} \mathrm{C}$ and $15,000 \times \mathrm{g}$ for $15 \mathrm{~min}$ and stored at $-80^{\circ} \mathrm{C}$ until the assay. The plasma E2 levels in the female eels were measured using an ELISA kit (DRG, Estradiol ELISA, EIA-2693).

In vivo hormonal treatment of male eels: measurement of sex hormones and gonadosomatic index (GSI)

Male eels weighing 300-500 g each, were injected intramuscularly with eel's ringer (control), hCG (1 IU/g of BW), rec-
FSH $(0.1 \mu \mathrm{g} / \mathrm{g}$ of BW $)$, rec-LH $(0.1 \mu \mathrm{g} / \mathrm{g}$ of BW $)$, and rec-FSH + rec-LH $(0.05 \mu \mathrm{g}+0.05 \mu \mathrm{g} / \mathrm{g}$ of BW $)$ once a week. After 3 and 8 injections, 8-10 eels were collected for blood sampling and GSI measurements. Blood samples were taken from the caudal vasculature with a heparinized $1 \mathrm{~mL}$ syringe and needle $(23 \mathrm{G})$ after anesthetization with 2-phenoxyethanol (200 ppm). The blood samples were centrifuged at $4{ }^{\circ} \mathrm{C}$ at $15,000 \times \mathrm{g}$ for $15 \mathrm{~min}$ and stored at $-80{ }^{\circ} \mathrm{C}$ until the assay. Plasma testosterone (T) and 11 -ketotestosterone (11-KT) levels in male eels were measured using an ELISA kit (MyBioSource, San Diego, CA, USA).

\section{Statistics Processing}

The differences in the means among groups were analyzed using Duncan's multiple range test.

\section{Results}

\section{In vitro E2 production in the culture of ovarian tissue}

The in vitro effects of rec-GTHs on E2 production in immature ovarian tissues are shown in Fig. 1. E2 levels were significantly higher in all treated groups than in the control group. Specifically, the highest E2 levels were achieved in groups treated with $0.1 \mu \mathrm{g} / \mathrm{mL}$ and $0.5 \mu \mathrm{g} / \mathrm{mL}$ of the rec-GTH.

\section{In vivo plasma E2 levels and gonadosomatic index (GSI) changes in female eels}

The changes in plasma E2 levels and GSI according to recGTHs and SPE administration are shown in Fig. 2. After 4 and 8 weeks of SPE administration, plasma E2 levels were significantly increased compared to the control. SPE treatment increased the E2 levels, as has been previously reported (Kim et al., 2007, 2008). However, the groups treated with rec-FSH and rec-LH achieved significantly increased the plasma E2 levels at 4 weeks after treatment, but there was no significant change in plasma E2 levels at 8 weeks compared to the control group. In the rec-FSH + rec-LH mixture treatment group, no significant changes were observed compared with the control group at 4 and 8 weeks after treatment. The GSI was significantly increased at 4 and 8 weeks after treatment compared to the control in the group treated with SPE. However, significant changes in GSI were not observed in any of the other groups.

\section{In vivo plasma T, 11-KT levels, and gonadosomatic index (GSI) changes in male eels}

The changes in plasma T, 11-KT levels, and GSI according to 


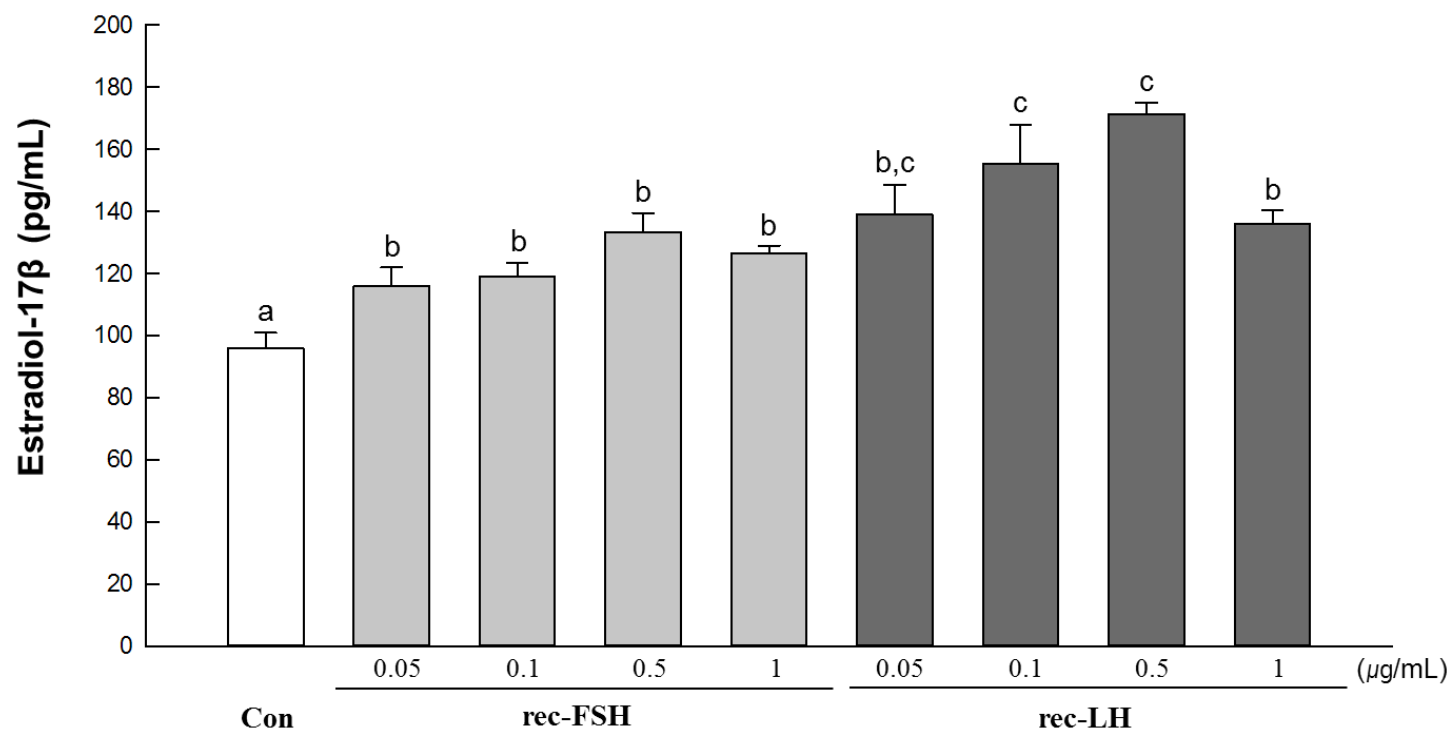

Fig. 1. In vitro effects of rec-GTHs on estradiol-17 $\beta\left(E_{2}\right)$ levels in the ovarian tissues of immature eel. Each value represents the mean and SEM $(n=6)$. The different letters indicate statistically significant differences $(p<0.05)$, according to Duncan's multiple range test. Con, hormone-free medium; rec-GTHs, recombinant eel gonadotropins; rec-LH, rec-luteinizing hormone.

rec-GTH and hCG administration are shown in Fig. 3. After 3 and 8 weeks of hCG administration, both plasma T and 11KT levels were significantly increased compared to those in the control group. Furthermore, the GSI in the hCG-treated group was higher than that in the control group. However, it should be noted that GSI and hormone levels were not different from those in the control group for all other groups treated with recFSH and rec-LH.

\section{Discussion}

The Japanese eel Anguilla japonica requires the administration of exogenous gonadotropins, such as SPE, for female eels, and hCG, for male eels, for the artificial induction of gonadal maturation. However, the eggs obtained thus far through exogenous hormone treatment have been known to be of poor quality, which results in lowering of fertility rates and induction of malformations (Shin, 2004). Furthermore, the milt obtained by injection of hCG showed individual differences in quantity and quality. To overcome these problems, species-specific recombinant GTHs were produced using silkworm larvae (Choi et al., 2016; Kim et al., 2008), mammalian cells (Molés et al., 2011), and Pichia pastoris (Kasuto \& Levavi-Sivan, 2005) as a bioreactor, and the biological activity of these gonadotropic reagents was evaluated and improved (Ohta et al., 2017). It is expected that species-specific GTHs of eels may induce a more efficient method of hormonal manipulation in the aquaculture of Japanese eel. In this study, we produced rec-GTHs from CHO-S cells and evaluated their bioactivity both in vivo and in vitro.

The in vitro results of this study confirmed that rec-GTHs affected early ovarian development. When an immature ovary was treated with rec-FSH or rec-LH, E2 levels increased compared to the control. In vertebrates, including teleosts, estradiol-17 $\beta$ (E2), which acts as a major steroid in vitellogenesis, promotes vitellogenin (Vtg) gene transcription, promotes egg yolk formation in oocytes, and increases during the vitellogenic phase of ovarian development (Nagahama, 1994). Furthermore, E2-induced Vtg expression in the liver of eels has also been demonstrated both in vitro and in vivo (Kazeto et al., 2011). Therefore, it is suggested that rec-GTHs may play a positive role in early ovarian development in female eels through in vitro ovarian E2 production. In contrast, there were no clear differences between the effects of rec-FSH and rec-LH on E2 production in early ovarian tissue. Our previous study (Kim et al., 2016) showed that rec-LH treatment had a positive effect on the induction of final maturation of eel oocytes. The potency of LH is considered more effective than that of FSH in oocyte maturation.

Although the in vitro effects of rec-GTHs on the sexual maturity of female eels were revealed in this study, there was no obvious in vivo effect of rec-GTHs on maturation induction 

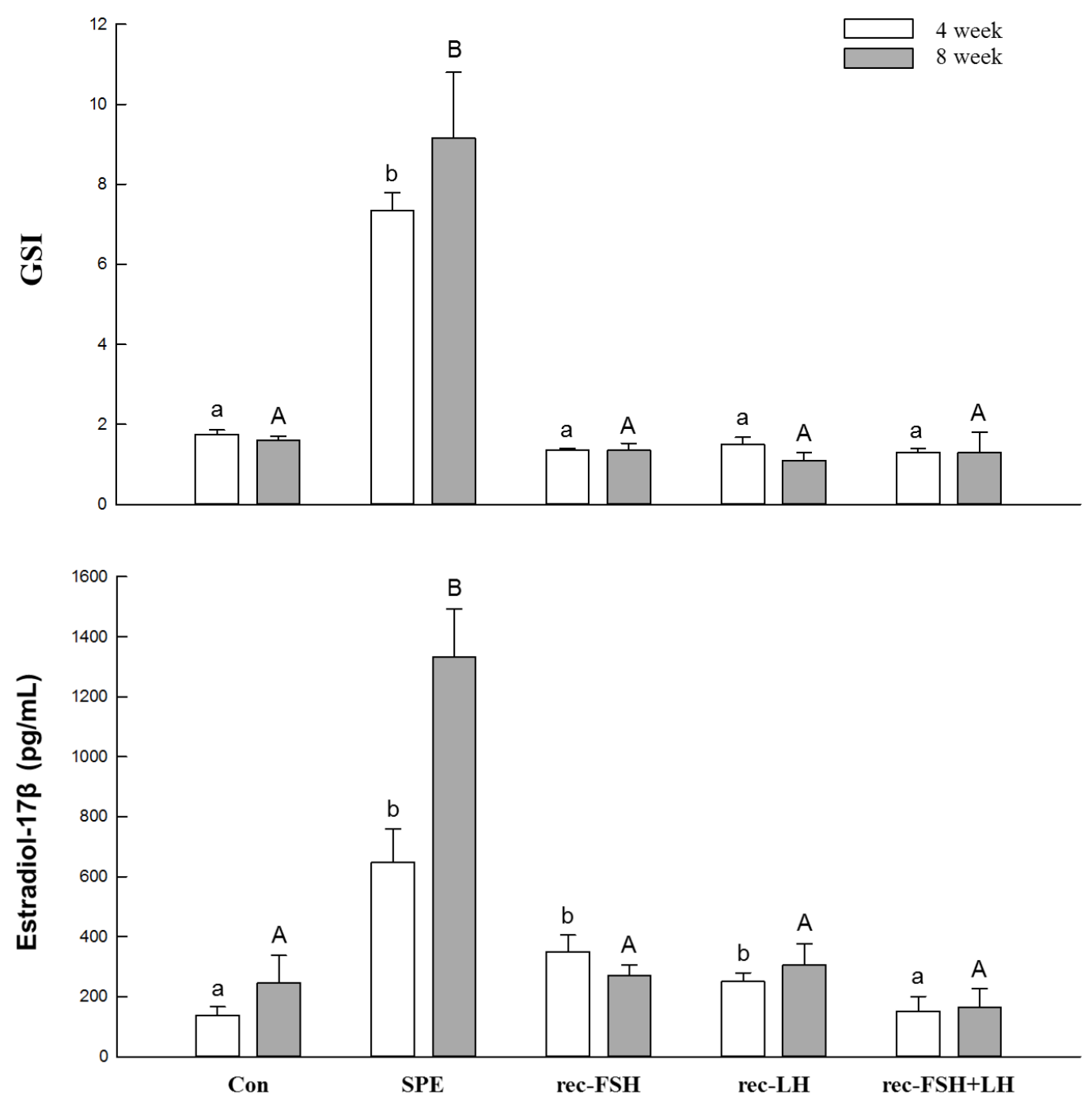

Fig. 2. In vivo effects of SPE and rec-GTHs on plasma estradiol-17 $\beta\left(E_{2}\right)$ levels and GSI of female eels. The SPE (20 mg/fish), recFSH $(0.1 \mu \mathrm{g} / \mathrm{g} \mathrm{BW})$, rec-LH $(0.1 \mu \mathrm{g} / \mathrm{g} \mathrm{BW})$, and rec-FSH + rec-LH $(0.05 \mu \mathrm{g}+0.05 \mu \mathrm{g} / \mathrm{g}$ BW) were administered weekly to immature female eels for 8 weeks. After 4 and 8 weeks, the GSI and plasma E2 levels of each experimental group were measured. The columns and bars indicate the mean and SEM. Differences shown using capital letters ( 8 weeks) and lowercase letters (4 weeks) above the bars indicate statistical significance ( $p<0.05)$, according to Duncan's multiple range test. Con, eel Ringer's solution; SPE, salmon pituitary extract; rec-FSH, rec-follicle-stimulating hormone; rec-GTHs, recombinant eel gonadotropins; GSI, gonadosomatic index; LH, luteinizing hormone.

in male and female eels. After 4 weeks of rec-GTH administration, the plasma E2 levels were higher than those in the control; however, no significant change was observed after 8 weeks of treatment. Furthermore, rec-GTHs exhibited slight effects on gonadal development. Similarly, the effects of hCG administration on GSI and plasma hormone concentrations in male eels were significantly higher than those in the control, whereas the effects of rec-GTH administration on the maturity of male eels were not apparent. The results of this study are similar to those from the study that analyzed the biological activity of recombinant GTHs in Japanese eels using Drosophila S2 cells (Kazeto et al., 2008). Kazeto et al. (2008) reported that rec-GTHs induced biological activity in vitro but did not induce definite activity in vivo. This difference between in vitro and in vivo bioactivities is probably due to the residual time of recombinant hormones in the blood. In other words, the absence of in vivo bioactivity of 

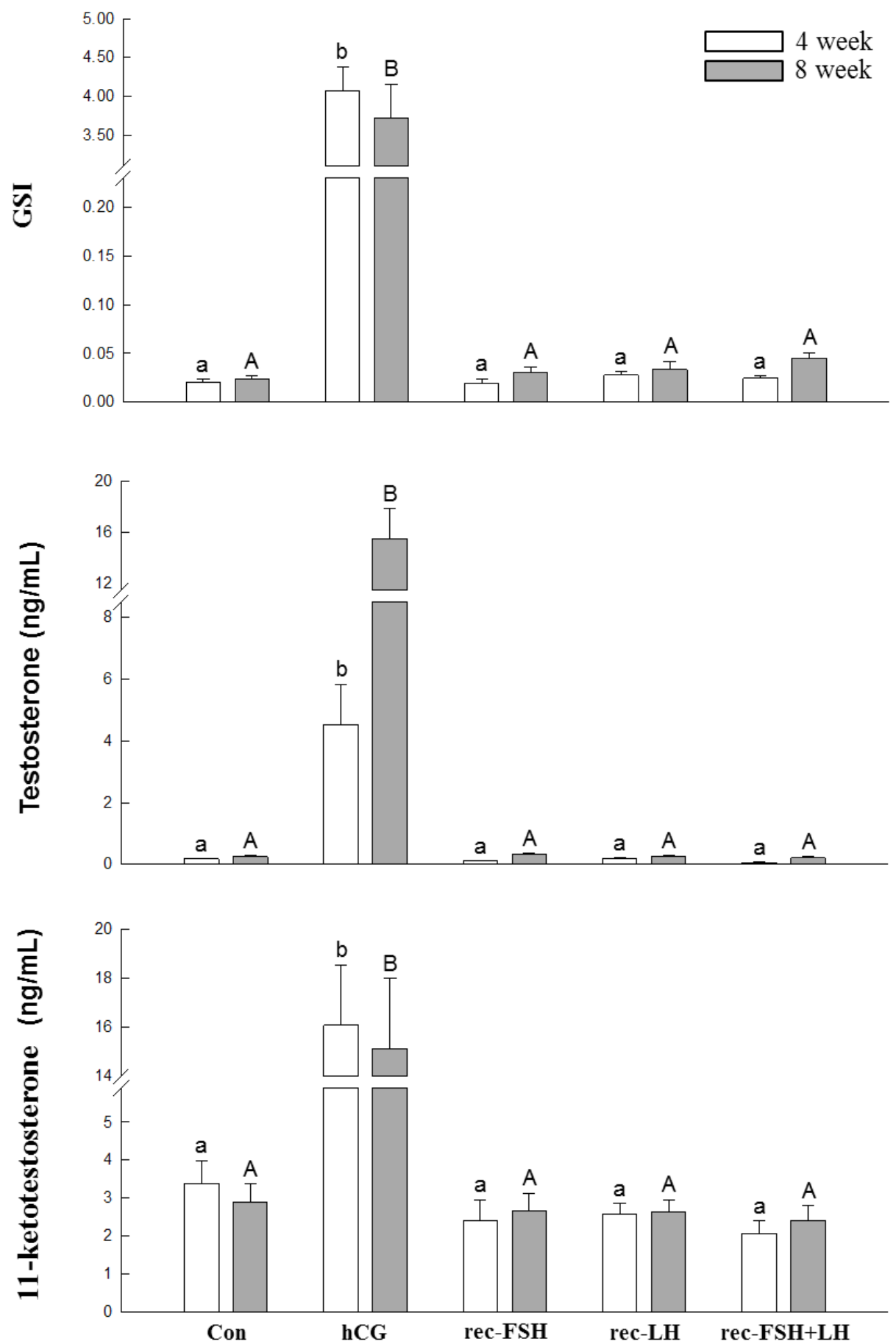

Fig. 3. In vivo effects of hCG, rec-GTHs on plasma testosterone, 11-ketotestosterone and GSI of male eels. The hCG (1 IU/g BW), rec-FSH $(0.1 \mu \mathrm{g} / \mathrm{g} \mathrm{BW})$, rec-LH $(0.1 \mu \mathrm{g} / \mathrm{g} \mathrm{BW})$, and rec-FSH + rec-LH $(0.05 \mu \mathrm{g}+0.05 \mu \mathrm{g} / \mathrm{g} \mathrm{BW})$ were administered weekly to immature male eels for maximally 8 weeks. After 3 and 8 weeks, GSI and plasma hormone levels of each experimental group were measured. The columns and bars indicate the mean and SEM. The capital letters ( 8 weeks) and lowercase letters ( 3 weeks) above the bars indicate statistical significance $(p<0.05)$, according to Duncan's multiple range test. Con, eel Ringer's solution; hCG, human chorionic gonadotropin; rec-FSH, rec-follicle-stimulating hormone; rec-GTHs, recombinant eel gonadotropins; GSI, gonadosomatic index; $\mathrm{LH}$, luteinizing hormone. 
rec-GTHs may be the result of the rapid clearance of the hormone in vivo. Legardinier et al. (2005) demonstrated that recGTHs have a rapid metabolic clearance in the blood; therefore, sufficient terminal sialylation of their carbohydrate chains is required to extend their half-life in blood. For this reason, recGTH bioactivity in female eels in this study was observed after 4 weeks of GTH administration but not at 8 weeks of administration. Therefore, it is necessary to confirm the half-life of recGTHs in the blood and to glycosylate the rec-GTHs with more complex and sialylated $\mathrm{N}$-glycans to induce bioactivity in vivo and to evaluate the in vitro biological activity of the rec-GTHs in male eels.

In the present study, we demonstrated that rec-GTHs clearly have positive effects on the sex maturation of immature ovarian cultures in vitro. However, the results showed no obvious effects in males in vitro, and in both genders under in vivo conditions. Thus, we suggest that further studies are needed on in vitro maturity induction of male eels, complement rec-protein production systems, and additional glycosylation of rec-hormones to extend the half-life of rec-GTHs in the blood.

\section{Competing interests}

No potential conflict of interest relevant to this article was reported.

\section{Funding sources}

This work was supported by the National Institute of Fisheries Science project (R2021012).

\section{Acknowledgements}

Not applicable.

\section{Availability of data and materials}

Upon reasonable request, the datasets of this study can be available from the corresponding author.

\section{Ethics approval and consent to participate}

This article does not require IRB/IACUC approval because there are no human and animal participants.

\section{ORCID}

Dae-Geun Kim

Jung-Hyun Kim

Hea-Ja Baek

Shin-Kwon Kim https://orcid.org/0000-0001-8064-4612 https://orcid.org/0000-0002-1991-9581 https://orcid.org/0000-0002-4578-5919 https://orcid.org/0000-0003-4508-9064
Kwan-Sik Min

Dae-Jung Kim

https://orcid.org/0000-0002-5451-3085

https://orcid.org/0000-0003-0832-3835

\section{References}

Byambaragchaa M, Kim DJ, Kang MH, Min KS. Site specificity of eel luteinizing hormone $N$-linked oligosaccharides in signal transduction. Gen Comp Endocinol. 2018;268:50-6.

Choi E, Ko H, Shin J, Kim MA, Sohn YC. Expression of gonadotropin genes in manchurian trout Brachymystax lenok and production of recombinant gonadotropins. Fish Sci. 2005;71:1193-200.

Choi JH, Kim DJ, Hong SM, Jo SJ, Min KS, Sohn YC, et al. Molecular analysis and bioactivity of luteinizing hormone from Japanese eel Anguilla japonica, produced in silkworm pupae. Biotechnol Bioprocess Eng. 2016;21:381-8.

Combarnous Y. Molecular basis of the specificity of binding of glycoprotein hormones to their receptors. Endocr Rev. 1992;13:670-91.

Hamidoghli A, Bae J, Won S, Lee S, Kim DJ, Bai SC. A review on Japanese eel (Anguilla japonica) aquaculture, with special emphasis on nutrition. Rev Fish Sci \& Aquacult. 2019;27:226-41.

Ijiri S, Tsukamoto K, Chow S, Kurogi H, Adachi S, Tanaka H. Controlled reproduction in the Japanese eel (Anguilla japonica), past and present. Aquac Eur. 2011;36:13-7.

Kagawa H, Iinuma N, Tanaka H, Ohta H, Okuzawa K. Effects of rearing period in seawater on induced maturation in female Japanese eel Anguilla japonica. Fish Sci. 1998;64:77-82.

Kamei H, Ohira T, Yoshiura Y, Uchida N, Nagasawa H, Aida K. Expression of a biologically active recombinant follicle stimulating hormone of Japanese eel Anguilla japonica using methylotropic yeast, Pichia pastoris. Gen Comp Endocinol. 2003;134:244-54.

Kasuto H, Levavi-Sivan B. Production of biologically active tethered tilapia $\mathrm{LH} \beta \alpha$ by the methylotrophic yeast Pichia pastoris. Gen Comp Endocrinol. 2005;140:222-32.

Kazeto Y, Kohara M, Miura T, Miura C, Yamaguchi S, Trant JM, et al. Japanese eel follicle-stimulating hormone (FSH) and luteinizing hormone (LH): production of biologically active recombinant FSH and LH by Drosophila S2 cells and their differential actions on the reproductive biology. Biol Reprod. 2008;79:938-46.

Kazeto Y, Tosaka R, Matsubara H, Ijiri S, Adachi S. Ovarian steroidogenesis and the role of sex steroid hormones on ovar- 
ian growth and maturation of the Japanese eel. J Steroid Biochem Mol Biol. 2011;127:149-54.

Kim DJ, Kim HW, Kim JH, Lee BI, Hong SM, Min KS, et al. Induction of sexual maturation in female eels Anguilla japonica by recombinant eel gonadotropin produced in silkworm. Korean J Fish Aquat Sci. 2017;50:770-6.

Kim DJ, Cho YC, Sohn YC. Molecular characterization of rockfish (Sebastes schlegeli) gonadotropin subunits and their mRNA expression profiles during oogenesis. Gen Comp Endocrinol. 2005;141:282-90.

Kim DJ, Bae JY, Kim EO. Changes in sex steroid hormones and ovarian development during artificial maturation of female eel, Anguilla japonica. Integr Biosci. 2007;11:117-24.

Kim DJ, Park WD, Son YC, Bae JY, Yun SJ, Son MH, et al. Maturation induction by manchurian trout recombinant gonadotropin hormone (mt-rGTH) in female eel, Anguilla japonica. Dev Reprod. 2008;12:261-6.

Kim DJ, Park CW, Kim DW, Park HK, Byambaragchaa M, Lee NS, et al. Production and characterization of monoclonal antibodies against recombinant tethered follicle-stimulating hormone from Japanese eel Anguilla japonica. Gen Comp Endocrinol. 2016;233:8-15.

Kim JM, Munkhuu O, Byambaragchaa M, Lee BI, Kim SK, Kang $\mathrm{MH}$, et al. Site-specific roles of $\mathrm{N}$-linked oligosaccharides in recombinant eel follicle-stimulating hormone for secretion and signal transduction. Gen Comp Endocrinol. 2019;276:37-44.

Kim HW, Kim JH, Kim DG, Jung MH, Ji SC, Yang SG, et al. Effect of artificially sexual maturation by hCG dose and injection interval in cultured male eel, Anguilla japonica. J Fish Mar Sci Educ. 2018;30:1578-86.

Ko H, Park WD, Kim DJ, Kobayashi M, Sohn YC. Biological activities of recombinant Manchurian trout FSH and LH: their receptor specificity, steroidogenic and vitellogenic potencies. J Mol Endocrinol. 2007;38:99-111.

Kobayashi M, Hayakawa Y, Park W, Banba A, Yoshizaki G, Kumamaru K, et al. Production of recombinant Japanese eel gonadotropins by baculovirus in silkworm larvae. Gen Comp Endocrinol. 2010;167:379-86.

Legardinier S, Duonor-Cérutti M, Devauchelle G, Combarnous Y, Cahoreau C. Biological activities of recombinant equine luteinizing hormone/chorionic gonadotropin (eLH/CG) expressed in Sf9 and Mimic insect cell lines. J Mol Endocrinol. 2005;34:47-60.

Miura T, Yamauchi K, Nagahama Y, Takahashi H. Induction of spermatogenesis in male Japanese eel, Anguilla japonica, by a single injection of human chorionic gonadotropin (Endocrinology). Zool Sci. 1991;8:63-73.

Min KS, Hattori N, Aikawa JI, Shiota K, Ogawa T. Site-directed mutagenesis of recombinant equine chorionic gonadotropin/luteinizing hormone: differential role of oligosaccharides in luteinizing hormone- and follicle-stimulating hormone-like activities. Endocr J. 1996;43:585-93.

Molés G, Zanuy S, Muñoz I, Crespo B, Martínez I, Mañanós $\mathrm{E}$, et al. Receptor specificity and functional comparison of recombinant sea bass (Dicentrarchus labrax) gonadotropins (FSH and LH) produced in different host systems. Biol Reprod. 2011;84:1171-81.

Nagahama Y. Endocrine regulation of gametogenesis in fish. Int J Dev Biol. 1994;38:217-29.

Ohta H, Kagawa H, Tanaka H, Okuzawa K, Iinuma N, Hirose $\mathrm{K}$. Artificial induction of maturation and fertilization in the Japanese eel, Anguilla japonica. Fish Physiol Biochem. 1997;17:163-9.

Ohta H, Sato Y, Imaizumi H, Kazeto Y. Changes in milt volume and sperm quality with time after an injection of recombinant Japanese eel luteinizing hormone in male Japanese eels. Aquaculture. 2017;479:150-4.

Okamura A, Yamada Y, Mikawa N, Horie N, Tanaka S, Tsukamoto K. Notochord deformities in reared Japanese eel Anguilla japonica larvae. Aquaculture. 2011;317:37-41.

Shin DH. Biochemical and histological studies on egg quality in the Korean eel (Anguilla japonica) [Ph.D. dissertation]. Sapporo, Japan: Hokkaido University; 2004.

Tanaka H, Kagawa H, Ohta H. Production of leptocephali of Japanese eel (Anguilla japonica) in captivity. Aquaculture. 2001;201:51-60.

Tanaka H. Progression in artificial seedling production of Japanese eel Anguilla japonica. Fish Sci. 2015;81:11-9.

Vischer HF, Granneman JC, Linskens MH, Schulz RW, Bogerd J. Both recombinant African catfish $\mathrm{LH}$ and FSH are able to activate the African catfish FSH receptor. J Mol Endocrinol. 2003;31:133-40.

Yamamoto K, Yamauchi K. Sexual maturation of Japanese eel and production of eel larvae in the aquarium. Nature. 1974;251:220-2.

Yaron Z, Gur G, Melamed P, Rosenfeld H, Elizur A, Levavi-Sivan B. Regulation of fish gonadotropins. Int Rev Cytol. 2003;225:131-85. 